\title{
La educación en Colombia: una reflexión propia sobre los procesos pedagógicos
}

\section{Education in Colombia: A self-reflection on the pedagogical processes}

\begin{abstract}
A educação na Colômbia: uma reflexão própria sobre os processos pedagógicos
\end{abstract}

\author{
Gina Mitchell Pérez Angulo \\ Licenciada en Lengua Castellana \\ Universidad Surcolombiana \\ mitchellperez2805@gmail.com
}

\section{Resumen}

En el presente artículo busco dar a conocer los momentos pedagógicos que nos formaron dentro del proceso docente en el que hoy nos encontramos. Así mismo, evidenciaré el por qué la educación estandarizada no es la respuesta a las necesidades contextuales de la educación en Colombia, para de esta forma proponer una pedagogía alternativa, a partir de las experiencias educativas de cuatro docentes que actualmente trabajamos con la Educación Propia con la comunidad ancestral Nasa del resguardo de Vitoncó en el municipio de Páez Cauca.

Palabras claves: Pedagogías alternativas, estandarización, educación escolarizada, aprendizaje significativo, contextualización.

\begin{abstract}
This article aims to make known the pedagogical moments that formed us within the teaching process in which we found ourselves today. Likewise, I will show why standardized education is not the answer to the contextual needs of education in Colombia, to propose an alternative pedagogy, based on the educational experiences of four teachers who are currently working
\end{abstract}


on Self Education with the Nasa ancestral community of the Vitoncó reservation in the municipality of Páez Cauca.

Keywords: Alternative pedagogies, standardization, schooled education, meaningful learning, contextualization.

\section{Resumo}

Neste artigo procuro divulgar os momentos pedagógicos que nos formaram no processo de ensino e em que nós encontramos hoje. Da mesma forma, mostrarei por que a educação padronizada não é a resposta às necessidades contextuais da educação na Colômbia, a fim de propor uma pedagogia alternativa, a partir das experiências formativas de quatro professores que atualmente trabalham com Educação Própria com a comunidade ancestral Nasa do Resguardo de Vitoncó no município de Páez Cauca.

Palavras-chave: Pedagogias alternativas, padronização, educação escolar, aprendizagem significativo, contextualização.

\section{Una corta historia}

Con el presente artículo iniciaré un proceso de reflexión pedagógica la cual empieza con los años escolares que cursé durante mi vida, es así como me permito hacerles partícipes de algunos momentos en mi historia escolar. Cursé mis primeros años de la educación inicial en escuelas privadas de la ciudad de Cali y finalicé la primaria en la escuela Sede Orito Dos del departamento del Putumayo. El bachillerato lo cursé en el colegio Liceo de Santa Librada de la ciudad de Neiva. Este tránsito por diferentes y diversos espacios escolarizados, me inquietó desde muy temprana edad hacia el ejercicio de la educación, pues reconocía en este escenario un motor fundamental en la construcción de sociedad, dado que en los diferentes modelos pedagógicos con los que me encontré, pude identificar ciertos factores diferenciadores que sólo hasta cursar mi pregrado en licenciatura, podría empezar a comprender más ampliamente.

Después de mi bachillerato, buscando darme un respiro antes de iniciar lo que sería la universidad, ingresé a la educación técnica; esta experiencia me mostró claramente hacia dónde estaba direccionado ese motor de la educación, hacia dónde está enfocado la construcción de la sociedad desde las lógicas nacionales, entendí que me estaban educando para el trabajo, para obedecer y poco o nada se estaba incentivando en mí, un ejercicio de generación de aprendizajes significativos para la 
vida o para el fortalecimiento de mi pensamiento crítico. Fue entonces, que busqué una alternativa en la universidad e ingresé a cursar la licenciatura en Lengua Castellana, pues en ese momento y aún hoy, considero a las universidades públicas como posibilitadoras de procesos reflexivos y promotoras del fortalecimiento del pensamiento crítico, aunque sobre esto último podríamos sentarnos y discutir con unas cuantas tazas de café.

Durante mis años de pregrado me encontré nuevamente con una educación escolarizada que continuaba reproduciendo contenidos bajo lógicas estandarizadas, dinámicas ajenas, escenarios inventados sobre nubes que ni siquiera se acerca un poco a lo que es la vida en los territorios colombianos. Sin embargo, había también un escenario paralelo a las jornadas de clases, escenarios que pude conocer gracias a mi estancia en la universidad pública; conocí procesos populares, procesos organizativos de estudiantes y comunidades que me motivaron en la búsqueda de alternativas pedagógicas.

Finalmente, una vez culminado mi plan de estudios de la carrera, tuve la oportunidad de dinamizar procesos en la educación propia con comunidades indígenas. Aquí, conocí otras docentes quienes también son hijas de este sistema de educación tradicional de nuestro país. Evidenciaré cómo este sistema de educación ha sido el causante de la apatía en los procesos educativos por parte del estudiante, ha sido perpetuador de un conocimiento occidental y mercantil, que poco o nada fortalece las identidades de nuestros pueblos indígenas, campesinos o afros; por el contrario, ha ido ocasionando una pérdida de nuestra memoria como pueblos pluriétnicos y ha llegado con una educación colonizadora homogeneizada.

Entonces, aquí nos encontramos, en el momento real y actual. Quiero por medio de esta reflexión, contarles el diálogo de nuestras historias, hacerles partícipes de los momentos pedagógicos que vivenciamos, los cuales no sólo están atravesados por la educación escolarizada, sino también por espacios pedagógicos alternativos que nos formaron como personas y como docentes, estas narraciones entrarán en diálogo constante con los planteamientos del educador popular Colombiano Marco Raúl Mejía, quien ha sido un referente fundamental en mi formación docente, es de la mano de sus postulados como expondré algunos retos de la educación en Colombia. De igual manera, les presentaré la alternativa pedagógica que buscamos movilizar en la institución, con el propósito de hacerle resistencia a una educación estandarizada e ir en la construcción de una educación para la liberación, una educación significativa, reflexiva, que prime sobre los saberes 
propios; pues gracias a estas últimas, es que hoy nos encontramos dinamizando procesos pedagógicos en este territorio ancestral, buscando dejar a un lado la escuela tradicional que nos formó.

\section{Paredes ajenas}

El encierro de la escuela permite que explique el mundo desde una lógica diferente de la que viven los actores por fuera de ella, en una supuesta universalidad en la cual quedan subsumidas las especificidades de nuestras realidades. (Mejía, 2017)

La mayor parte de la población colombiana ha cursado sus estudios escolares y profesionales en centros educativos formales, los cuales son regidos por unas normativas nacionales direccionadas por el Ministerio de Educación Nacional (MEN). A su vez el MEN responde a unas políticas educativas internacionales que evalúan constantemente los desempeños en las competencias de sus estudiantes. Lo interesante de estas políticas, es que son emitidas por organismos cuyos intereses están enfocados al comercio, tales como lo son la Organización para la cooperación y el Desarrollo Económico (OCDE) y el Banco Mundial. Por ejemplo, el decreto 2450 de 2015 y la Resolución 2041 de 2016 emitidas por el MEN, son reformas a las licenciaturas que buscan orientar a estos programas en las competencias necesarias para alcanzar los lineamientos internacionales. De esta manera, se evidencian unas dinámicas de estandarización del aprendizaje, una educación al servicio de los poderes económicos que no responde a ninguna necesidad contextual, ni está pensada acorde a las realidades sociales colombianas.

Ahora bien, esta búsqueda de seguir lineamientos internacionales se presenta ante nosotros como una posibilidad para que nuestro país obtenga mayores inversiones internacionales, alcance un "desarrollo" y se abra espacio entre la sociedad de investigación y demás; pero ¿a qué desarrollo se le está apuntando? ¿En beneficio de quiénes está el alcanzar estos estándares? Marco Raúl Mejía señala: "Nunca antes como hoy, son tan explícitas las relaciones que existen entre educación y propuesta de país, de sociedad y de desarrollo que se realice. Es decir, la propuesta de sociedad va en forma de currículo, estándares, competencias, pedagogías, al hecho educativo, no como una simple reproducción, sino bajo la especificidad del mismo" (Meía, 2014). Es decir, toda la forma en que se ha organizado la educación en Colombia está al servicio del poder económico, la educación no se está pensando como una herramienta liberadora, ni que fortalezca la identidad de los pueblos, sino por el contrario, apunta a una homogenización del conocimiento y un utilitarismo de las personas como sujetos técnicos 
moldeados para el trabajo y para cumplir un rol de servicio dentro de la sociedad de consumo capitalista.

En este orden de ideas, podemos pasar a revisar la memoria de nuestra vida escolar. Detenernos y volver a las jornadas de clase en la escuela. Preguntarnos si los conocimientos que allí nos orientaron estaban enfocados a pensar nuestras realidades, a fomentar una mirada crítica sobre los roles de clases que desempeñamos y cómo estos determinan las posibilidades de vida que hoy estamos experimentando. Podemos también revisar si las escuelas que nos formaron estaban en contacto con nuestra vida cotidiana o si, por el contrario, éstas eran paredes ajenas en donde pasábamos seis o más horas dentro de una nube que poco o nada significa para nuestro día a día.

Nos detendremos aquí, en el papel de la escuela dentro de todo este engranaje, pues es finalmente el lugar físico en donde todas estas políticas mercantiles se materializan. Mejía señala: "El encierro de la escuela permite que explique el mundo desde una lógica diferente de la que viven los actores por fuera de ella, en una supuesta universalidad en la cual quedan subsumidas las especificidades de nuestras realidades" (Mejía, 2017), de esta manera, la escuela se convierte en un lugar ajeno para los estudiantes; en este modelo educativo, desarrollan un papel pasivo en donde sólo cumplen el rol de receptores. Un segundo actor, los docentes, quienes son la persona encargada de "transmitir los conocimientos", no están buscando generar un aprendizaje significativo con base a las realidades vivenciales de los receptores, pues sólo se limita a cumplir con unos estándares y contenidos predispuestos en un currículo generalizado que busca una "universalidad" dejando a un lado las particularidades del lugar en donde se entra a incidir.

A través de las entrevistas podremos evidenciar la escuela como lugar alejado de nuestras realidades contextuales y cómo esto nos lleva a reconocer unas características de las y los docentes. Estas fueron algunas de las respuestas de las entrevistadas al preguntar sobre ¿cómo concebía el ejercicio docente durante sus años escolares?

- Laura Bahamon: En el colegio yo tuve unos profesores muy hartos, aburridos, siempre con el mismo sonsonete.

- Manuel Perdomo: Del hombre que llega con los libros gastados debajo del brazo, a decir siempre lo mismo de todos los años a descargar muchas veces las furias y los pesares que trae desde la casa desde su mismo trabajo como profesor.

- Mitchell Perez: Veía a los docentes como unos entes muy 
lejanos, iluminados y ahora recapacito sobre el hecho de que yo no veía a mis docentes como personas iguales que yo, para mí eran perfectos, no tenían una vida personal, eran como esa persona que llegaba al salón muy preparada con sus cosas y ya eso era todo.

Este accionar docente que se describe, lo podemos enmarcar dentro de la pedagogía frontal o "instruccionista", denominada por Marco Raúl Mejía, en donde señala lo pedagógico como el proceso en el cual el maestro o la maestra es la base del mismo, en cuanto a que es la persona encargada de entregar ese acumulado que el alumno no posee y que sería considerado como un déficit en su desarrollo (Mejía, 2017). Pero, ese papel que ejecuta el docente dentro de este modelo instruccionista, tiene unas bases ideológicas, políticas e incluso mercantiles. En este sentido, los y las docentes desarrollan el papel de reproductores del sistema económico al que ya nos hemos referido, se encargan de alienar al estudiante bajo estas normativas. Johana Campo, una de las entrevistadas, es indígena del pueblo ancestral Nasa y toda su vida vivió en su comunidad, sobre esta misma pregunta, cuando salió del resguardo a terminar sus estudios, nos cuenta:

Yo terminé el grado 11 en La Plata-Huila. Estudiaba los domingos y trabajaba de lunes a sábado. Una vez estábamos hablando del tema de las universidades públicas y privadas y la profesora decía que en las universidades los indígenas no podían entrar a estudiar que porque éramos pobres, que la universidad era para gente adinerada y pues uno cree que todo lo que el profe dice es la verdad. Entonces cuando la profe me decía eso, yo decía, pues bueno, yo soy indígena, soy pobre, me toca trabajar y estudiar, pues nunca llegaré a una universidad privada ni pública.

Con esto quiero evidenciar un par de factores relacionados a la reproducción del sistema mercantil y la alienación de los estudiantes. Nos encontramos en primer momento con una estudiante indígena que debe desplazarse de su lugar de origen para continuar con sus estudios. En muchas ocasiones culminar los estudios para los jóvenes indígenas es bastante dificultoso, ya sea por situaciones económicas complicadas, problemáticas contextuales con el conflicto rural, familias que no encuentran relevante el estudio, falta de instituciones educativas cercanas a los poblados, entre otras. Por otro lado, nos encontramos con una docente que encarna fielmente el rol de reproductora del sistema, busca acortar las posibilidades de formación académica de sus estudiantes y puntualmente de su estudiante en condiciones económicas menos favorecidas y que además pertenece a una comunidad indígena. 
¿Esto sucede de forma inocente? Estoy convencida de que no hay planteamientos puestos al azar dentro del sistema de educación, esta docente, al igual que muchos otros, fue educada para reproducir unos lineamientos ideológicos específicos, cada nueva política o cada recorte presupuestal a la educación, están determinados por unos intereses productivos que benefician a una clase social muy específica de nuestro país. Al respecto Mejía señala: “... las corrientes pedagógicas buscan fijar un norte para la sociedad en la que actúan y para los intereses particulares de la acción educativa y las implicaciones de esas opciones en la constitución de lo social" (Mejía, 2017). Entonces aquí entramos a una educación capitalista, la cual no contempla diferencias culturales, no fortalece la identidad del estudiante, no promueve alternativas para la vida individual y colectiva, sólo necesita mantener a las clases de arriba con el control de las clases de abajo. Nos encontramos con una educación que no dialoga con el contexto, ni reconoce las formas de pensamientos alternativos.

\section{Una realidad contextual}

Ahora quiero presentarles el territorio en donde tiene lugar esta propuesta pedagógica. En primer momento, buscaré ubicar al lector dentro del contexto de la comunidad, pues considero que es necesario realizar un reconocimiento del territorio con el fin de construir la propuesta pedagógica acorde a las realidades y necesidades específicas. Además, el centrarnos en las dinámicas propias del territorio, nos posibilita tejer un accionar directo con las reflexiones que este artículo busca presentar con relación al deber ser del docente en los procesos pedagógicos.

El Cauca es un departamento que se ha visto afectado a lo largo de la historia por los diferentes conflictos armados de Colombia, así es como podemos evidenciarlo en la época de la violencia bipartidista, por ejemplo; más tarde, con la incursión de los grupos guerrilleros como el M-19, el EPL, ELN, FARC-EP, grupos paramilitares, como también han hecho presencia bandas criminales organizadas que tienen el poderío de las redes de narcotráfico en la zona, esto último, producto de las condiciones con las que cuenta el territorio para el cultivo de plantas que sirven de base para esta industria, al igual que la falta de presencia del Estado, además de ser un corredor del occidente del país hacía el Pacífico.

Dentro de los grupos guerrilleros, aquel que más ejercía influencia en la zona eran las guerrillas de las FARC-EP, fue a partir de las negociaciones planteadas en el Proceso de Paz con el Gobierno Nacional en el 2016, que se pudo generar un ambiente de relativa tranquilidad en relación con esta guerrilla; sin 
embargo, esto también dio pie al posicionamiento de nuevos grupos alzados en armas que empezaron a ejercer control en la zona. Posterior al comunicado emitido en agosto de 2019, por una facción de las FARC-EP que no se sintió representada con la implementación de los acuerdos, se ha visto agudizado nuevamente el conflicto en este territorio. Ésta es la situación de orden público en la que se encuentra actualmente la zona en donde está ubicado el colegio en el que laboramos, un proceso de retomar las tierras que fueron dejadas durante el acuerdo de paz y que hoy se encuentran en el poderío de bandas criminales.

Por otro lado, a partir de los años 60's las comunidades indígenas han liderado procesos de resistencia, recuperación de sus Territorios y exigencia del Derecho Propio como comunidades ancestrales. Esto se ha visto evidenciado con la fundación del Consejo Regional Indígena del Cauca (CRIC) y asociaciones de cabildos que administran todo lo relacionado con la Educación Propia, Sistema de Salud Propia, Soberanía Alimentaria y Territorial, las cuales se encuentran respaldadas por la Ley de Transferencias. Lo mencionado, son todos logros de las constantes disputas desde la movilización comunitaria, la protesta social y la fuerza de la guardia indígena apoyada por cada comunero y comunera.
Una de las grandes disputas de las comunidades indígenas consistió en la recuperación de la autonomía en el ámbito educativo, puesto que anteriormente la educación era regulada por el Ministerio de Educación Nacional (MEN) que, bajo unas lógicas de la estandarización de los conocimientos, desconocía de muchas formas los saberes propios y ancestrales de las comunidades aborígenes y sus necesidades contextuales. En respuesta a este panorama, las comunidades campesinas, afrodescendientes e indígenas, replantean las directrices trazadas por los Proyectos Educativos Institucionales (PEI). Es así, como inicia el camino para la construcción de una nueva propuesta que responda a las necesidades educativas comunitarias y que realmente contribuya al fortalecimiento de los tejidos de saberes y conocimientos de los contextos; durante este proceso, se empiezan a tejer todas las bases para la construcción del Proyecto Educativo Comunitario (PEC) que busca fortalecer los saberes propios de las comunidades desde sus realidades específicas al tiempo que se teje un diálogo con los saberes occidentales. Esto último es una de las estrategias que han encontrado las comunidades para permitir el diálogo entre las políticas externas que de diferentes maneras han permeado las lógicas propias del buen vivir; sin embargo, a partir del PEC se busca hacer frente a estas dinámicas por medio de la educación, herramienta fundamental para garantizar la 
pervivencia de los pueblos aborígenes.

El colegio en el que nos encontramos dinamizando procesos educativos, fue fundado en el año 1996 como respuesta a la necesidad de la comunidad de contar con un centro educativo al que pudieran acceder con mayor facilidad los y las comuneras del resguardo; dado que antes de éste, debían desplazarse hasta la cabecera municipal para realizar sus estudios en el colegio $\mathrm{La}$ Normal de Belalcazar. En un principio el colegio respondía a la normativa del PEI, fue a partir del 2002 donde se empezó a forjar la transición hacia el PEC de la mano con la comunidad y del Sistema Indígena de Educación Propia (SEIP).

Es así como hoy en día la comunidad cuenta con un instituto de carácter Etno Ecológico, pues busca fortalecer los valores culturales y la cosmovisión de la comunidad en relación con el buen vivir y el reconocimiento del territorio como Ente Vivo. Además, se imparte una educación bilingüe, dado que en el territorio se habla la lengua nativa Nasayuwe como forma de vida $y$ de reconocimiento de su memoria como pueblo ancestral, ya que es a partir de su lengua como se mantiene viva la herencia cultural del pueblo; del mismo modo, se practica el español como segunda lengua dada la importancia de mantener un diálogo con el resto del país en defensa de los derechos ancestrales que por tantos años vienen exigiendo.

\section{Un accionar docente alternativo}

Siendo múltiples las caras de la dominación, son múltiples las resistencias y los agentes que las protagonizan. En la ausencia de un principio único, no es posible reunir todas las resistencias y agencias bajo el amparo de una gran teoría común, más que de una gran teoría común lo que necesitamos es una teoría de la traducción, que haga mutuamente inteligibles las luchas y permita a los actores colectivos 'conversar' sobre las opresiones a las que se resisten $\mathrm{y}$ las aspiraciones que los animan. (Santos, 2003)

Debo precisar que las docentes entrevistadas somos todas egresadas de la Facultad de Educación de la Universidad Surcolombiana sede Neiva. Johana Campo y Laura Bahamón son egresadas del programa de la Licenciatura en Artística, por otro lado, Manuel Perdomo y yo, Mitchell Pérez, somos egresadas del programa en Licenciatura en Lengua Castellana.

Cuando ingresé como docente a la institución, me encontré con unas dinámicas educativas que distaban significativamente de los conocimientos que recibí durante el pregrado, fue así que identifiqué una serie de retos para 
llevar a cabo mi accionar docente. Quiero señalar que estos "retos" no son sino vacíos como docente educada en un pregrado que desconoce dentro de su currículo, la diversidad cultural del país; sin embargo, estas falencias, han sido la razón fundamental para repensarnos propuestas alternativas que hagan frente a las realidades contextuales.

En primer momento, señalaré una característica fundamental que supuso un gran reto en nuestro ejercicio docente, en el colegio el 98\% de los estudiantes tiene como lengua materna el nasayuwe. Lo señalo como reto, pues dada nuestra formación, no teníamos los elementos para hacer frente a esta riqueza cultural, puesto que la comunicación entre los estudiantes y las docentes que no hablamos el nasayuwe, no siempre fluye de la mejor manera. Durante las entrevistas, todas señalamos este factor como uno de los retos más significativos:

\section{¿Cuál cree ha sido el mayor} reto de la experiencia docente en el resguardo?

- Laura Bahamon: La lengua, no quisiera perderme de eso que dicen. Porque como no entiendo todo lo que hablan a veces, eso es como una pequeña barrera. El no poder uno expresarse o dar a conocer sus ideas de una forma más clara para ellos, de manera adecuada, genera dificultades en la comunicación.
- Johana Campo: Cuando llegué al colegio fue como un choque porque de igual manera de tanto estar en la ciudad se me había olvidado hasta el Nasayuwe, hablarlo bien, hablaba nasayuwe sin sentido, sin sabor, como se dice. Entonces los compañeros se burlaban de cómo yo hablaba y me sentía mal, porque no era mi culpa, sino la universidad y el haber estado en la ciudad.

- Manuel Perdomo: Una característica principal es que los estudiantes hablan en cierta medida el español, pero sus ascendencias son provenientes de otra lengua y es una de las cuestiones que más me llama la atención, pero también me deja desarmado pedagógicamente para poder desarrollar todo lo que uno quiere, porque me formé como profe de español para hispanohablantes, pero las lógicas cambian bastante cuando el estudiante no le entiende a usted la mayoría de lo que está diciendo. El manejo de las dos lenguas genera inexactitudes en la comunicación.

- Mitchell Perez: Creo que precisamente mi desconocimiento de la lengua, porque uno se siente excluido de muchas conversaciones, lo cual imposibilita el poder alcanzar ciertos grados de comprensión en el habla. Entonces muchas veces yo sentía cuando daba clases de español durante el primer año, que los chicos y las chicas de sexto no comprendían en su 
totalidad, ciertas cosas que yo estaba hablando. No es un problema de ellos, sino una dificultad que yo tenía, porque probablemente en nasayuwe ellos habrían podido tener un acercamiento más significativo sobre lo que yo estaba enseñando.

Frente a este escenario, en esta ocasión, sólo quiero lanzar una interrogante, ¿por qué razón, en la mayoría de los programas de formación universitaria es obligatorio el aprender el inglés como segunda lengua $y$ no lenguas nativas de nuestro país? $\mathrm{Al}$ respecto Freire con relación a la reflexionando sobre la educación en Latinoamérica, señala que el paradigma latinoamericano centra su propuesta en una crítica a la modernidad, en cuanto a que su pretendida universalidad significa una violencia epistemológica que niega formas de conocer fundadas en la cultura y el contexto, como terreno de diferencia, y en la necesidad de que la educación construya actores críticos, promotores de transformación de sus realidades (Freire, 1975). Es decir, que bajo las lógicas de una "educación universal", lo que se viene haciendo es un desconocimiento de los saberes propios, generando que las identidades de los pueblos ancestrales nos resulten menos importantes que los requisitos académicos para competir en el mercado internacional. Por esta razón, desde la institución los y las docentes buscando cambiar esta idea colonizadora desde el lenguaje, propusieron cambiar las lógicas, desde las dinámicas propias, es así como en la institución no se celebra "El día del Idioma", como en la mayoría de las instituciones de nuestro país, sino que se conmemora "El día de las lenguas"; de esta manera, se busca hacer énfasis en las riquezas culturales que se tienen en nuestro país y en el mundo. Durante el Día de las Lenguas los y las estudiantes leen poesía en español, interpretan obras de teatro en nasayuwe, cantan en inglés y se hace un reconocimiento de la gran diversidad idiomática que tenemos como pueblos.

Un siguiente factor diferenciador de la educación en este contexto, es la propuesta pedagógica del colegio, pues ésta se enmarca desde el PEC, esto conlleva necesariamente a construir un proceso educativo de la mano con las dinámicas propias del resguardo, comprender las disputas de la comunidad y fortalecer, por medio de la escuela, la identidad del pueblo ancestral. Por esta razón, se hizo necesario empezar a conocer sus costumbres y su cosmovisión no únicamente desde lo teórico, sino a través de lo vivencial.

Los y las docentes no sólo vivimos en el resguardo, sino que nos integramos a las dinámicas diarias del mismo. Participamos en los trabajos comunitarios convocados por los y las comuneras; nos integramos en las asambleas 
comunitarias en donde se discute y se construye colectivamente el Plan de Vida del resguardo, cada decisión que se lleva a cabo en la comunidad, se dialoga en asamblea y conjuntamente se llegan a acuerdos comunitarios. Esta forma de organización política es completamente ajena a lo que vivimos las personas que no pertenecemos a estas comunidades. Por ende, resulta una experiencia sumamente significativa en el ejercicio docente, puesto que el docente, no es una figura confusa, dotada de todos los conocimientos y que viene a cumplir con unos contenidos específicos, sino por el contrario, el docente reconoce al estudiante como un sujeto igual con el que se entra en un diálogo de saberes, en un constante tejido de lo que yo como decente sé, lo que el estudiante como sujeto activo aporta y lo que juntos creamos en el ejercicio pedagógico. Con relación a esto, en las entrevistas se preguntó acerca de ¿cómo describiría la experiencia docente que viene desarrollando en la institución?

- Laura Bahamon: Es un aprendizaje constante que me permite redescubrirme, aprender de mí como persona, como docente. Ha sido un aprendizaje colaborativo por mi lado $\mathrm{y}$ también de parte de los estudiantes.

- Johana Campo: En artística trabajamos todo lo que son tejidos propios del pueblo nasa y de otros pueblos. Me da mucha alegría compartir lo poquito que yo sé, entrar en diálogo con ellos, porque de eso se trata el tejido, de transmitir a los muchachos porqué el tejer, como yo les digo a ellos, tejer no sólo es sentarse y coger hilo y aguja, sino entender y comprender por qué se teje, por qué el nudo, por qué el tejido queda con hueco, todo el sentido y el significado espiritual que trae el tejido.

- Manuel Perdomo: Hay que hacer el intento de mediar entre los dos mundos, con el mundo comunitario y con el mundo estandarizado de la educación en Colombia. Lo que se puede hacer realmente es mucho, no hay limitaciones marcadas, no hay una cámara siguiéndonos a todas partes y es una ventaja para poder desarrollar lo que uno pretende. Entonces pienso que lo que yo hago es tratar de mediar, primero entre los dos mundos de la legislación educativa, los estándares de la educación y el mundo comunitario, qué es lo que es significativo para ellos y lo que resulta pertinente para el contexto y de qué manera podemos entrar en diálogo con estas dos cuestiones para poder lograr juntos con los muchachos que el estudio no lo veamos como algo impuesto, molesto, fastidioso sino ver cómo empezamos a entenderlo juntos.

- Mitchell Pérez: Ha sido una experiencia de crecimiento personal, no sé si todo lo que yo estoy aprendiendo en el resguardo 
es directamente proporcional a lo que yo les pueda llegar a compartir. Trabajar en una comunidad indígena es entender lógicas diferentes, sentir las cosas de forma diferente, a relacionarme con mi entorno, con el contexto, con la naturaleza y con las personas de forma diferente. Entonces vivir y pervivir, como plantan los indígenas, en un contexto indígena es muy significativo y más que como docente se espera que pueda seguir arraigando en los estudiantes esas dinámicas y esa forma de sentipensar el mundo desde mi ejercicio docente.

Finalmente, lo que he denominado como "retos" no son más que las evidencias del sistema de educación estandarizado con el que contamos en nuestro país: sin embargo, una forma de hacerle frente a estas realidades educativas, es convertir estos restos en oportunidades de vivenciar una educación alternativa, una lucha desde el aula por contribuir en la construcción de una sociedad que reconoce sus riquezas culturales, que fortalece la memoria de los pueblos; es una oportunidad de enfocar el accionar docente en un ejercicio de transformación social.
Investigación en Educación Global y para el Desarrollo.

Mejía, M. R. (2017). Educación y pedagogías críticas desde el sur. Cartografía de la educación popular. Buenos Aires: Grupo Editorial Parmenia.

Santos, B. d. (2003). Crítica de la razón indolente. Contra el desprecio de la experiencia. Bilbao: Desclée de Brouwer.

\section{Referencias}

Freire, P. (1975). La Pedagogía del Oprimido. Madrid.

Mejía, M. R. (2014). Urgencias de la educación latinoamericana. Revista Internacional sobre 